\title{
Promoting renewable energy and energy efficiency in Central Africa: Cameroon case study
}

\author{
Joseph Kenfack $^{1, *}$, Médard Fogue ${ }^{1}$, Oumarou Hamandjoda ${ }^{1}$, Thomas Tamo Tatietse ${ }^{1}$ \\ 1. National Advanced School of Engineering, Yaounde, Cameroon \\ * Corresponding author. Tel: +23799416002, Fax:+23722229116, E-mail: joskenfack@yahoo.fr
}

\begin{abstract}
Central Africa owns important renewable energy potential. This important potential is still suffering from poor development. The main cause of the poor use of renewable energy is the poor commitment and dedication of governments who have not taken the necessary measures to boost the sector. Thermal plants are hence among other solutions planned or under construction. The purpose of this paper is among other things aiming at ensuring that the renewable energy resources of Central Africa are known and are subject to be used optimally. The work also shows availability of renewable energy sources and suggests actions to promote and sustain its development. Based on the knowledge of the Central African energy sector, this paper will identify actions for improved access to sustainable, friendly, affordable energy services to users as well as a significant improvement of energy infrastructure in Central Africa and the promotion of renewable energy and energy efficiency. The work will show the potential for solar, biomass and hydro while showing where available the level of development. Then identified obstacles for the promotion of clean energy will be targeted. Finally, suggestions will be made to help the countries develop a vision aiming at developing good clean energy policy to increase the status of renewable energy and better contribute to fight against climate change. Cameroon case study will be examined as illustration. We will use several documents from institutions in the region and abroad, and maps when available.
\end{abstract}

Keywords: Renewable energy, Potential, Central Africa, energy policy, Cameroon

\section{Introduction}

Central Africa owns important renewable energy potential, namely hydro, solar and biomass. This important potential is still suffering from poor development up to the point where the sub region is still abundantly using the fossil energy as main power source. The main cause of the poor use of renewable energy is the poor commitment and dedication of governments who have not taken the necessary measures to boost the sector. This issue will also be addressed. Since the region is experiencing power shortage, thermal plants are among other solutions planned or under construction. This solution currently under implementation in Cameroon and other countries in the region, is not environment friendly and hence is not a long term solution.

\section{Methodology}

The work shows availability of renewable energy sources and suggests actions to promote and sustain its development. Based on the knowledge of the Central African energy sector, this paper will identify actions for improved access to sustainable, friendly, affordable energy services to users as well as a significant improvement of energy infrastructure in Central Africa and the promotion of renewable energy and energy efficiency.

The work will show at first the potential for the three primary energy sources which are solar, biomass and hydro while showing where available the level of development. Then identified obstacles for the promotion of clean energy will be targeted. Finally, suggestions will be made to help the countries develop a vision aiming at developing good clean energy policy to increase the status of renewable energy and better contribute to fight against climate change. Cameroon case study is very interesting because the country has a great renewable energy potential and can develop and export energy to neighboring countries. 
The state of art in energy sector in Cameroon will be made. Based on ongoing projects and strategic documents adopted by the country, directions towards which actions will be made will be suggested. From the overview of institutional structure reform of the Cameroon power sector and assessments, specific suggestions based on the weaknesses of the institutions will be made for the enhancement of the renewable energy and hence sustain energy access and security in general and in remote areas in particular, where the fight against poverty is more difficult. We will use several documents from institutions in the region and abroad, and maps when available.

\section{General information on Central Africa}

Central Africa (Cameroon, Central African republic, Gabon, Republic of Congo, Chad, Equatorial Guinea, Democratic republic of Congo) is situated between latitude $13^{\circ}$ south and latitude $22^{\circ}$ north, longitude $8^{\circ}$ East and longitude 22 East.

Central Africa is endowed with an abundance of renewable energy resources but the region is still looking forward to facing the challenge of harnessing its resources effectively and efficiently. There is still a vast dependence on fossil fuels and biomass. The use of fuel wood for lighting and cooking is still very familiar in the region given the poor income of populations. This negatively impacts the environment and causes infant mortality from acute respiratory illness associated with the inhalation of wood smoke. Approximately 1.6 million people die every year because of indoor air pollution - that's one death every 20 seconds [1]. This indicates that there is a need to develop efficient, sustainable and safe technologies to relieve population from such a burden.

\section{Renewable energy potential in central Africa}

\subsection{Hydro potential}

These countries own important hydro potential. Although $3.4 \mathrm{GW}$ has already been developed, above 100 more GW of hydro power still remain untapped with an economically feasible hydropower potential above 900 TWh. Given the importance of the hydrographic network, tidal energy can also be envisaged, as well as ocean energy along the guinea golf.

Table 1 Thermal power, hydropower potential and development in Central Africa: source: [2] and [3]

\begin{tabular}{ccccc}
\hline COUNTRY & $\begin{array}{c}\text { Gross theoretical } \\
\text { hydropower potential } \\
\text { (TWh/year) }\end{array}$ & $\begin{array}{c}\text { Under } \\
\text { operation in } \\
1999(\mathrm{MW})\end{array}$ & $\begin{array}{c}\text { Technically } \\
\text { feasible } \\
\text { (TWh) }\end{array}$ & $\begin{array}{c}\text { Thermal } \\
\text { plants }\end{array}$ \\
\hline CAMEROON & 294 & 725 & 115 & 300 \\
\hline GABON & 80 & 170.2 & 32 & 210 \\
\hline $\begin{array}{c}\text { DEMOCRATIC } \\
\text { REPUBLIC OF } \\
\text { CONGO }\end{array}$ & 1397 & & & NA \\
\hline CONGO & 50 & 2440 & 774 & 24 \\
\hline $\begin{array}{c}\text { CENTRAL AFRICA } \\
\text { REPUBLIC }\end{array}$ & NA & 89 & NA & \\
\hline $\begin{array}{c}\text { EQUATORIAL } \\
\text { GUINEA }\end{array}$ & NA & 19 & 3 & 37 \\
\hline CHAD & & 1 & NA & \\
\hline
\end{tabular}




\subsection{Wind potential}

According to GEOS-1 satellite measures from NASA [Error! Bookmark not defined.] from july 1983 to june 1993, the wind potential of the region is poor within the equator. Chad is the only country with an average speed above $5 \mathrm{~m} / \mathrm{s}$ throughout the country, allowing the possibility for wind development.

\subsection{Geothermal potential}

Some hot water sources are identified in the region, but detail study for the assessment of the geothermal potential have not yet been done so far in Central Africa, although one important volcano (mount Cameroon) is still in activity. The eastern part of the Democratic Republic of Congo might have important geothermal potential since it is part of the Indian Ocean ring of fire.

\subsection{Solar Potential}

Africa is situated from one side to another at the Equator level, hence making this continent one of the sunniest in the world. Based on the data from Solar Radiation project (SoDa) [4], the lowest daily mean radiation ranges from around $4 \mathrm{kWh} / \mathrm{day} / \mathrm{m}^{2}$ (wet forest) to above 8kWh (dry desert in Chad). The modified map below from SoDa shows the average solar radiation of the region. It appears that Central Africa has a great solar potential.

\subsection{Biomass Potential}

Central Africa holds up to one-quarter of the world's tropical forests. This forest is the second largest tropical forest in the world after the Amazon forest. Its mosaic of ecosystems regulates local climate and the flow of water. The forest covers an important area, from the Albertine Rift (Rwanda, Burundi, Uganda) to the Gulf of Guinea (Equatorial Guinea, Gabon, Cameroon) and harbors a variety of forest. It's one of the place where wild dense forests can still be found in the world with an area around 500 million acres, spanning the boundaries of Cameroon, the Central African Republic, the Democratic Republic of Congo, Equatorial Guinea, Gabon and the Republic of Congo.

Inadequate and improper forest management practices is a threat to the long-term viability of these forests, significantly reducing their economic potential and resulting in negative social and environmental impacts. Over 50 percent [5] of the Congo Basin's forests are under commercial logging leases. Despite several sustainable forest management programs, Central Africa tropical forests are disappearing at an alarming rate.

\section{The energy sector in the region}

The energy sector differs from one country to another, depending on the available potential. Some countries have liberalized the sector and others are still on the way to doing it. Each country has its own energy sector management and regulations. The countries are still looking forward to having transborder regulations. This will for instance facilitate grid interconnection and sustainable management of energy sources. All the countries have developed important thermal plants.

\section{Energy efficiency}

The issue of energy efficiency is suffering from poor information and dissemination on energy efficiency technologies. The contributions in Central Africa should mainly be oriented towards building capacities and information dissemination on energy efficiency technologies. The grand objective of this initiative is to lighten the economical burdens of the countries in 
the region thereby improving the life quality. Due to the reason of affordable prices, most of the countries are using, less efficient equipment notably in their industry, transportation or household sectors (generator, wood, petrol...). Most of such equipment, which can be secondhanded (from developed countries), obsolete or of inefficient technology (non efficient stoves, incandescent light bulb...), is less efficient than the latest models being used to date and thus consumes more energy. These inefficient apparatuses often produce more air pollutants that can cause environmental destruction and threat of contracting serious diseases for people.

Many countries in Central Africa are oil producers. The availability of fossil fuels is hence not an important issue. The energy efficiency technology could help reducing the negative environmental impact of human activities by decreasing the consumption of fossil fuels, and thereby yielding the same results as the renewable energies. Actions should be undertaken to ameliorate and sustain the Energy Intensity, defined here as the ratio of the total energy consumption to the Gross Domestic Production (GDP), to a level below 0.5 (developed countries between 0.2 and 0.3 ).

Introducing high efficiency technologies into Central Africa will be foreseen to lighten their economical burden by reducing the total conventional fuel consumption, electricity bills and the high deforestation level, and thus improving their productivity. Given the high level of biomass consumption (80\% household energy in Cameroon [6]), energy efficiency will be foreseen to lighten the desert encroachment and thus climate change.

The issue of implementing hybrid renewable energy system can also be envisaged, namely solar/hydro/biomass/wind.

\section{Barriers to renewable energy and efficient energy implementation}

There are significant barriers to the further implementation of renewable energy that need to be addressed. The key issues include the following:

- Biomass, hydro, solar and wind energy technologies remain expensive (high capital costs), compared to firewood, charcoal, petrol and gas energy supplies,

- Poor long period support of renewable energy projects (till reaching profitability)

- Lack of consumer awareness on benefits and opportunities of renewable energy solutions.

- Poor decentralized solutions for energy services (generation, distribution...)

- Financial, legal, regulatory and organizational barriers need to be overcome in order to implement renewable energy technologies and develop markets.

- Lack of specific access to key energy infrastructure such as the national electricity grid,

- Poor availability of funds for development of renewable energy

- Poor organization and sector institutions

\section{Suggestions}

\subsection{Vision}

The region needs to develop a vision leading to strategies and programs. This should be politically sustained in order to mitigate the poor leadership and poor renewable energy and energy efficiency policy formulation in the sector. In order to sustainably fight against climate change, strategic action plans should be developed or reviewed where available to fit with clean development mechanism. This should be done through capacity building and capacity enhancement of stakeholders in the region. 
Central Africa in general is suffering from a poor vision on the issue of renewable energy and energy efficiency. Very few countries have developed a vision on this issue and other are still looking forward to doing it. The strategies and programs exist in some countries. They should match the vision and meet the targets.The region should identify the long term perspective action on the issue of promoting renewable energy and energy efficiency. Where there is no vision on this issue, it is important to focus on stakeholder's capacity to define and adopt a long-term perspective on renewable energy and energy efficiency. If need be, capacity building and/or capacity enhancement should be prior to the formulation of the vision.

In order to meet the renewable energy and energy efficiency targets, effective leadership is a key issue for the attainment of the targets within Central Africa. At national and regional levels, political authorities should be involved and support the action. This would lead to the generation of champions.

Other important points are:

- $\quad$ enforce energy policy at the regional level,

- promote and develop power trade and ancillary services,

- increase access to clean energy to populations and reduce poverty,

- create a free regional energy market and improve energy system reliability and quality of supply in the whole region.

- initiate pilot projects funded to help develop the market for sustainable energy,

- create favorable regulatory and policy frameworks,

- Promote innovative finance and business models to activate the private sector,

- develop and support policy-maker networks at regional level with initiatives in the field of energy efficiency, sustainable energy regulation, renewable energy and regional regulatory board

- disseminate mirroring of well-reasoned input

\subsection{Enabling environment}

Given the purchase power of the population and the economic constraints, renewable energy requires an enabling environment for its promotion. As mentioned above, the renewable energy initial capital cost is high compared to conventional energy sources. This can only lead to making them commercially uncompetitive in the short to medium-term. To overcome this situation, specific actions need to be taken at several levels, namely fiscal, financial, social and legislative levels. This includes commitment and dedication of actors for a good leadership and encouragement of champions. National and international bodies hosting development agencies based in each country should also work together to attain the promotion of renewable energy and energy efficiency targets. Full implementation of free trade within Economic Community of Central African States (ECCAS) will facilitate regional programs and collaboration among states.

Addressing the human resource issue is a key point for attaining the objectives. The region experiences poor human resources in the field of designing, evaluating and implementing renewable energy and energy efficiency projects. Good governance and good regulation in the sector are also very important for promoting and enabling environment for scaling up investments and mobilizing public and private initiatives.

The real potential and benefits of all renewable energy sources is still to be assessed. Because some studies are not done or not fully done, the costs for developing renewable energy tend to 
be very high and there is a reluctance to invest in what are sometimes considered to be risky investments.

\subsection{Role of financial instruments}

The profitability of renewable energy is subject to discussion in a market driven energy economy. To address this issue, many countries in Europe have adopted different specific renewable power generation approaches (feed in tariff, certificates, fixed tariff). In order to achieve the target, the introduction of renewable energy technologies into a market driven energy economy will require the allocation of funding to assist in overcoming the initial high capital cost. It could be done through government bodies, private institutions sustained by government or simply through dedicated funds (budgetary allocation, subsidies, incentives...). The process should be stopped as soon as the renewable energy technologies become competitive and are driven by market forces alone.

Other actions to be undertaken are:

- Establishment of a good organizational framework and robust energy policy and strategy

- Public sensitization

- Promotion of efficient techniques and marketing strategies (4Ps)

- Knowledge management and networking with other partners and projects, governmental and private sector partnership

\section{Cameroon case study}

Cameroon power sector heavily relies on hydropower with $721 \mathrm{MW}$ of Hydro schemes over the total installed capacity of above 1000MW. According to the World Bank Investment Climate Assessment, limited access to reliable electricity is among the 5 top obstacles to doing business in Cameroon. It is estimated that the lack of reliable energy services is costing Cameroon close to $2 \%$ of the gross domestic product growth. In order to rehabilitate existing power station, as well as transmission and distribution networks, the electricity utility AES SONEL recently secure a EURO 260 million loan financing for its five year investment program. In order to secure energy supply for the country, the Government of Cameroon commissioned a least cost power sector development plan (PDSE 2030) which is on the way to being updated. Given the time needed for the studies, development and funding of hydro plants, the country has been obliged to take emergency measures based on thermal solutions to cover current and foreseen energy shortages in the short term. If the funding doesn't follow, emergency measures taken for electricity production might become permanent, producing more than one million tons of carbon dioxide per year.

\subsection{Main current and future thermal plants}

From 2004 to 2011, thermal plants capacity from fossil energy has been multiply by four. Several thermal plants are permanently under operation. The most important are the Limbe thermal plant and the Yassa thermal plant with an installed capacity of $85 \mathrm{MW}$ each. The construction of Kribi thermal plant (gas) with a capacity of up to $300 \mathrm{MW}$ is ongoing. To meet energy shortage foreseen in the country in the short term, the Government plants plans to develop up to $100 \mathrm{MW}$ additional thermal capacity in the cities of Bamenda (20 MW), Ebolowa (10 MW), Mbalmayo (30 MW) and the capital city Yaounde (40 MW). To face the growth of the demand estimated above $50 \mathrm{MW}$ per year, important reforms and midterm development plans have been done. As demonstrated above, renewable energy is far from being the first solution for addressing energy shortage issues in Cameroon. 


\subsection{Institutional reform}

Prior to the current status, electricity was supplied in Cameroon by a single vertically integrated company that had the responsibility for production, transmission, distribution and retail sales. The country established a sector regulator (ARSEL), a rural electrification Agency (AER) and also created the Electricity Development Corporation (EDC) which, as Government of Cameroon's asset holding company, is responsible for the management of public sector assets in the power sector, in particular hydropower assets, as well as the regulation of power flows. Nowadays, more than 20 texts govern the sector which is liberalized since 1998. The aim of liberalization was to attract private sector investments to help the country develop its power sector. The generation, transmission, distribution and sales of power are submitted to concession agreement, license or authorization, declaration regime, free regime and the special regime for rural electrification.

\subsection{Renewable energy promotion}

No specific action dedicated to the promotion of renewable energy has been undertaken so far. Programs for efficient stoves are ongoing for energy efficiency but many other issues still to be addressed. The country also has a rural electricity fund for the promotion of rural electricity. The formulation of strategic actions to boost the energy sector in all parts of the country is still ongoing in the Ministry of Energy and Water. The promotion of renewable energy and energy efficiency is among these actions. But given the poor experience of the stakeholders, pilot projects should be initiated and disseminated.

\subsection{Identified regulatory barriers to renewable energy}

Challenges (regulatory and others) to sustainable energy in Cameroun include:

- The restructuring of the electricity utility AES-SONEL mission;

- The establishment of connection charges and tariffs from renewable sources;

- The update and implementation of low cost solutions and safety standards for rural electrification;

- The encouragement of the ongoing policy for entrepreneurs willing to enter the electrical service contracting business;

- The consolidation of the provision of incentives to encourage entry of new electricity retailers in cities and rural areas through rural electrification fund;

- The promotion of energy efficiency

- The dissemination of bests practices.

The mission of the electricity utility should be restructured to encourage energy from renewable sources, through attractive connection charges and feed in tariffs. In order to boost the sector, the rural electricity fund should promote the development of hydro and solar plants where need be and disseminate information about champions.

\subsection{Weaknesses of the institutions}

The country will be experiencing in the future for the first time a true management of new operators, for only two licenses are granted so far. All the projects are currently facing poor visibility on the issue of feed-in, transport and tariffs. The electricity regulatory agency (ARSEL) created in the framework of liberalization hence has limited experience.

For each of the ongoing projects, there will be specific negotiations if necessary measures concerning regulations are not taken in time. The sector is also suffering from a lack of 
transborder regulation for interconnection among countries, because Cameroon can be a net electricity exporter. Options for encouraging decentralized solutions in remote areas are currently ongoing through rural electricity fund, but the experience is still limited. To address these issues, Cameroon is developing several strategic action plans. The promotion of renewable energy and energy efficiency hence still has a long way to go.

\section{Conclusion}

Central Africa is a region with great renewable energy potential, a place were almost all renewable energy sources can be found. The region owns the first hydro potential of the continent, the second tropical forest in the world and an important solar radiation all year long. Despite the great renewable energy potential, the region is experiencing very poor renewable energy and energy efficiency promotion. Although some actions are ongoing, more specific actions in the region are needed at several levels. Suggestions have been made to help the region develop a good vision to address the issue and take the necessary measures at all levels for promoting renewable energy and energy efficiency.

\section{References}

[1] WHO, Fact sheet $N^{\circ} 292$, June 2005

[2] Aqua Media International, Word Atlas and Industry guide, The International journal on Hydropower\&Dams, 2009, pp 64-68

[3] Conseil mondial de l'énergie, Potentiel de développement intégré de l'énergie au plan régional en Afrique : Document de Travail, 2003

[4] http://www.soda-is.com

[5] http://www.tropicalforestfoundation.org/projects/gabon

[6] Ministère de l'énergie et de l'eau, Système d'information énergétique du Cameroun, rapport 2007

[7] Hanchery, overview of the National Hydropower Study: the Value, Potential, and Role of Hydropower as a Future Energy Source”, Proceedings Waterpower '79: An International Conference on Small Scale Hydropower, U.S. Army Corps of Engineers and U.S. Department on Energy, 1979, pp.675-680,

[8] P. Maher, N.P.A. Smith, A.A Williams, Pico hydro power for rural electrification in developing countries, International Journal of Ambient Energy, Vol 19 Number 3, July 1998

[9] Société Nationale d’Electricité du Cameroun, Atlas du Potentiel hydroélectrique du Cameroun, Sine loco, 1983. 